\title{
Anthropometric study of cephalic index among medical students in Nepal
}

Timsina RP1, Gogoi P2

${ }^{1}$ Ram Prasad Timsina, Lecturer; ${ }^{2}$ Paramananda Gogoi, Professor; Department of Anatomy, Kathmandu Medical College Teaching Hospital, Kathmandu, Nepal.

\section{Abstract}

Background: Cephalic index is the ratio of the maximum breadth of head to its maximum length that is expressed as a percentage. Anthropometric measurements, especially craniofacial measurements, are important for determining various head and face shapes. These anthropometric studies are conducted on the age, sex and racial/ethnic groups in certain geographical zones.

Objectives: The objectives of this study were to find out racial classification and their differences in Nepalese medical students anthropologically and to compare these with the data from other ethnic caste for use in anthropometric and forensic studies.

Method: This is a descriptive and cross sectional study on 940 undergraduate medical students of age 17 to 27 years, with 455 males and 485 females from the three different medical colleges of Nepal. The head length (cm) and breadth $(\mathrm{cm})$ were measured by spreading calliper. The height $(\mathrm{cm})$ and weight of the participants were recorded. All the collected data were summarized using statistical package for social sciences (SPSS) 16.0 versions and their significance was tested by student t- test.

Results: The mean cephalic index of 455 males and 485 females were $80.99 \%$ and $83.34 \%$ respectively. The cephalic index varied from the range of 71.20 to 97.40 in female and 72.08 to 96.77 in male. The dominant type of head shape in our study was mesocephalic (50.76\%) followed by brachycephalic (32.74\%).

Conclusion: This study showed the head type of Nepalese was brachycephalic predominant but with the tendency to mesocephalic and hyperbrachycephalic.

Key words: Anthropometry, Cephalic index, Head breadth. Head length

\section{INTRODUCTION}

A nthropometry is the systematic technique for measuring and taking observations on man, his skeleton, the skull, the limbs, trunk etc as well as the organs by the most reliable means and scientific methods ${ }^{1}$. The anthropometrics studies are conducted on the age, sex and to find out racial and sexual differences in certain geographical zones. Cephalic index and head shape are greatly affected by geographical, sex, age and racial factors.

Anthropometry deals with the techniques for measuring different parts of the human body as well

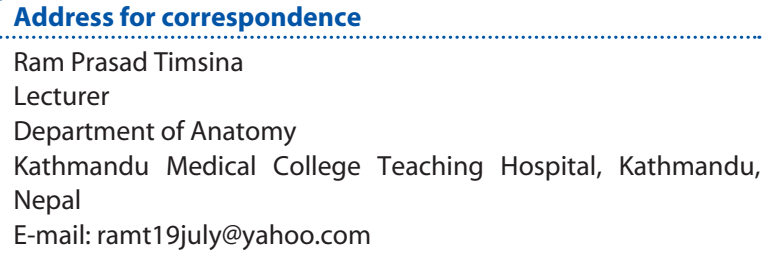

as the human skeleton. Accordingly, anthropometry includes somatometry and osteometry. Somatometry deals with the measurement of the living body or the cadaver including their head and face. But osteometry is concerned with the measurement on the skeletal bones other than skull. However, cephalometry is concerned with the measurement on the head and face. Cephalic index is the ratio of the breadth of the head to its length that is expressed as percentage. The index is obtained by dividing the maximum width of the cranium by its maximum length and multiplying by 100 .

\section{METHODS}

Nine hundred and forty (455 males and 485 females) undergraduate Nepalese medical students with age range from 17 years to 27 years were taken as a participants from the three different medical colleges of Nepal from March 2010 to March 2012 after approval from the ethical committee. The major caste Brahmin, Kshetry, Newar and Mangoloid with other scheduled 
caste data were calculated. Rai, Limbu, Magar, Gurung, Sherpa and Tamang communities were placed in mongoloid groups and Tharu, Shah, Singh; Biswokarma etc. were mentioned as unspecified schedule caste. The informed consent from the participants was taken.

The participants were asked to sit comfortably on a stool in relaxed condition with head in anatomical position. The maximum head length ( $\mathrm{MHL}$ ) was measured as greatest anteroposterior diameter with the help of spreading calliper from glabella to inion. The maximum head-breadth (MHB) was measured as the maximum transverse diameter between two fixed parietal eminences points. The participants were advised to stand straight against the vertical scale of height machine without shoes or slippers and measurement for total stature was taken. Those having any craniofacial deformity were excluded.

Cephalic Index $=($ Head breadth $/$ Head length $) \times 100$

The result of the cephalic index was presented in four groups on the basis of international anatomical descriptions by William et al (1995)'.
Table 1: Classification of head shape based on cephalic index ${ }^{1}$.

\begin{tabular}{lc|}
\hline Head shape & Range of cephalic index (\%) \\
\hline Dolicocephalic & $<75$ \\
\hline Mesocephalic & $75-79.9$ \\
\hline Brachycephalic & $80-84.9$ \\
\hline Hyperbrachycephalic & $>85$ \\
\hline
\end{tabular}

All the collected data were summarized using statiscial package for social sciences (SPSS) 16.0 versions and their significance was tested by student t- test.

\section{RESULTS}

The summary of the results of the various parameters are presented in table 2 to 3 and comparisons of cephalic indices between various ethnic groups are presented in table 4-6.

Among the participants, mean stature was $160.61 \mathrm{~cm}$, mean weight $55.60 \mathrm{~kg}$, mean head length $17.54 \mathrm{~cm}$, mean head breadth 14.39, mean head height $15.01 \mathrm{~cm}$ and mean cephalic index 82.04. Gender-wise, mean cephalic index of 455 male students was 80.99 while that of 485 female students was 83.38 ( $p$ value $<0.001$ ). The cephalic index varied from the range of 71.20 to 97.40 in females and 72.08 to 96.77 in males.

Table 2: Age wise distribution of participants.

\begin{tabular}{|lcc|}
\hline Categorized age & Frequency & Percentage \\
\hline $17-21$ yrs & 717 & 76.3 \\
$22-27$ yrs & 223 & 23.7 \\
\hline Total & 940 & 100 \\
\hline
\end{tabular}

Table 3: Frequency of community wise mean height and $\mathrm{CI}$

\begin{tabular}{lccccccc}
\hline \multirow{2}{*}{ Community } & \multicolumn{2}{c}{ Frequency } & \multicolumn{2}{c}{ Mean height $\mathbf{( c m )}$} & \multicolumn{2}{c}{ Mean Cl } \\
\cline { 2 - 7 } & Male & Female & Male & Female & Male & Female \\
\hline Brahmin & 123 & 141 & 167.10 & 155.80 & 80.46 & 83.25 \\
Kshetri & 119 & 126 & 164.30 & 156.57 & 81.85 & 83.48 \\
\hline Newar & 83 & 115 & 164.31 & 156.37 & 80.81 & 83.72 \\
Mangoloid & 53 & 48 & 165.49 & 154.14 & 81.29 & 84.43 \\
\hline Others & 77 & 55 & 165.59 & 155.30 & 80.52 & 81.83 \\
\hline
\end{tabular}

Table 4: Caste-wise distribution of various head shapes

\begin{tabular}{|c|c|c|c|c|c|c|}
\hline Head type & Brahmin & Kshetri & Newar & Mongoloid & Others & Total \\
\hline Dolicocephalic & 6 & 6 & 5 & 1 & 8 & 26 \\
\hline Mesocephalic & 92 & 72 & 61 & 36 & 52 & 313 \\
\hline Brachycephalic & 109 & 93 & 76 & 36 & 42 & 356 \\
\hline Hyperbrachycephalic & 57 & 74 & 56 & 28 & 30 & 245 \\
\hline Total & 264 & 245 & 198 & 101 & 132 & 940 \\
\hline
\end{tabular}


Table 5: Results of head shape and gender wise classification

\begin{tabular}{|c|c|c|c|c|}
\hline \multirow{2}{*}{ Head type } & \multicolumn{2}{|c|}{ Gender } & \multirow{2}{*}{ Total } & \multirow{2}{*}{ P value } \\
\hline & Male & Female & & \\
\hline Dolicocephalic & 5 & 21 & 26 & \multirow{5}{*}{0.015} \\
\hline Mesocephalic & 231 & 82 & 313 & \\
\hline Brachycephalic & 149 & 207 & 356 & \\
\hline Hyperbrachycephalic & 70 & 175 & 245 & \\
\hline Total & 455 & 485 & 940 & \\
\hline
\end{tabular}

Table 6: The cephalic index in different student groups

\begin{tabular}{|c|c|c|c|c|c|}
\hline \multirow{2}{*}{ Study group } & \multirow{2}{*}{ Workers } & \multicolumn{2}{|c|}{ Number } & \multicolumn{2}{|c|}{ Cephalic Index } \\
\hline & & Male & Female & Male & Female \\
\hline Kasturba Medical College, Manipal, India. & Vaishali KY(2012)² & 66 & 34 & 77.92 & 80.85 \\
\hline $\begin{array}{l}\text { Dr. Pinnamaneni Siddhartha Institute of } \\
\text { Medical Sciences and Dr. Sudha \& Nageswara } \\
\text { Institute of Dental Sciences India. }\end{array}$ & Salve VM $(2011)^{3}$ & 160 & 160 & 75.68 & 78.20 \\
\hline Ogbia students of Baysela state, Nigeria & Erije $M A(2010)^{4}$ & 219 & 221 & 73.68 & 72.24 \\
\hline B.J Medical College, Gujarat, India. & Shah GV and Jadhav HR $(2004)^{5}$ & 302 & 198 & 80.42 & 81.20 \\
\hline Kaa, Bori and Okwale & Oladipo GS (2009) ${ }^{6}$ & 400 & 400 & 111.18 & 75.09 \\
\hline Nepalese students & Present study & 455 & 485 & 80.99 & 83.38 \\
\hline
\end{tabular}

\section{DISCUSSION}

In the present study, the mean Cephalic index $(\mathrm{Cl})$ of males was 80.99 which is slightly higher than that of Indian Barels 79.80 and Bhils $76.98^{7}$ and similar to finding in Gujarati males $80.42^{5}$. This finding is lower than the $\mathrm{Cl}$ in population in south of $\operatorname{Iran}^{8}$ (82.4) and Chile ${ }^{9}$ (81.51).

The dominant type of head shape in our study was mesocephalic $(50.76 \%)$ followed by brachycephalic (32.74\%) and hyperbrachycephalic (15.38\%).

The brachycephalic head types of Indian males (33\%) and Turkmen (42.4\%) in north Iran ${ }^{10}$ was similar to finding with this study. The dolicocephalic (1.09\%) was a rare head type of our study but it was found in seven percent of Indian Guajarati and in nine percent in Tehran ${ }^{5,10}$.

The cephalic index of Nepalese female in this study was 83.38. This was higher than in the study by Shah and Jadhav ${ }^{5}$ in Indian females (81.20) and Ognis female of Nigeria $^{4}$ (75.09).

Infemales, the dominant types of head was brachicephalic (42.68\%) followed by hyperbrachycephalic (36.08\%) and mesocephalic (16.9\%). The study done by Vaishali ${ }^{1}$ showed dominant type of head was brachycephalic in $33 \%$ of female while it was $49 \%$ in females of Gujarat ${ }^{5}$. The rarely present head type in this study was dolicocephalic (4.32\%).
The dominant head type of ethnic groups like Brahmin, Kshetri and Newar in present study was brachycephalic while in Mongoloid and other groups dominant head type was mesocephalic. The cephalic index in present study of mongoloid group was 81.29 in males and females 84.43 in females. This is similar to the study done by Lobo et al. ${ }^{11}$ on Gurung community of Nepal where $\mathrm{Cl}$ of male was 83.1 and for female was 84.6.

Our study showed cephalic index of Kshetri was 82.65 which fall in the brachycephalic. The different studies of people of North India showed the mean value of all population less than 76.0 which fall in the dolicocephaly category. It showed Kshetri were brachycephalic and Tharus were in mesocephalic. The old Nepalese and Gurkha were having meso to brachycephalic index $(78.09)^{12}$

The study carried by $M K$ Bhasin $^{13}$ observed brachicephalic elements among the Indian population groups with Mangoloids, Tibetans, Bhotia, Burman, Lepcha, Limbus, Khambus and Gurung. The mean values of $\mathrm{Cl}$ among them were 76.06 which were facing to mesocephaly category. But our study of Mongoloids showed brachicephalic and mesocephalic head type with $35.64 \%$ each.

\section{CONCLUSION}

The present study showed the anthropometrical 
variations in cephalic index. The magnitude of the cephalic index varies significantly in different ethnic groups. The findings of the study can be utilized as evidence based scientific data on the era of cephalic index diagnosis and in establishing racial burden of the society. This research work provides valuable diagnostic and prognostic information that can be used for further studies in Nepalese community.

\section{REFERENCES}

1. Williams P, Dyson M, Dussak JE, Bannister LH, Berry MM, Collins P, et al. Gray's anatomy. 38th ed. London: Elsevier Churchill Livingston; 1995, p. 607-12.

2. Vaishali KY, Shakunthala RP, Sneha G, Kalthur C, Hemalatha PI. Study of cephalic index in Indian students. Int J Morphol. 2012;30(1):125-9.

3. Salve VM, Thota NR, Patibandala A. The study of cephalic index of Andhra Region (India) Asian J Med Sci. 2011:53-5.

4. Eroje MA, Fawehinmi HB, Jaja BN, Yaakor L. Cephalic index of Ogbia tribe of Bayesla state. Int J Morphol. 2010; 28:389-92.

5. Shah GV, Jadhav HR. The study of cephalic in students of Gujarat. J Anat Soc Ind. 2004;55:25-6.

6. Oladipo GS, Olotu J. Anthropometric comparison of cephalic indices between the ljaw and Igbo tribes. Global J Pure Appl Sci. 2006;12:137-8.

7. Bhargava I, Kher GA. A comparative anthropometric study of Bhills and Barelas of central India. J Anat Soc Ind. 1961;10:126-33.

\section{ACKNOWLEDGEMENT}

Authors acknowledge Kathmandu Medical College Teaching Hospital for financial assistance to conduct this study and we are thankful to BPKIHS and KIST Medical College for providing their undergraduate medical students and help for completion of this work as a subject of present study. We are grateful to all the students for their voluntary participation.

8. Golalipour MJ, Haidari K, Jahanshahi M, Frahani MR. The shapes of head and face in normal male newborns in South East of Caspian Sea (IranGorgan). J Anat Soc Ind. 2003;52:28-31.

9. Del Sol M. Cephalic index in a group of mapuche individuals in the IX Region of Chile. Int J Morphol. 2005;23:241-6.

10. Abolhasanzadeh A, Farahani MR. Standarded international classification of head shapes of 22-24 years old in Tehran. J Res Med. 2003;26:281-5.

11. Lobo SW, Chandrashekhar TS, Kumar S. Cephalic index of Gurung Community of Nepal- An anthropometric study. Kathmandu Univ Med J. 2005;3(3):263-5.

12. Anitha MR, Vijaynath V, Raju GM, Vijayamahantesh SN. Cephalic index of North Indian population. Anatomica Karnataka. 2011;5(1):40-3.

13. Bhasin MK. Genetics of castes and tribes of India; Somatometry. Int J Human Genet. 2006; 6(4):32356. 